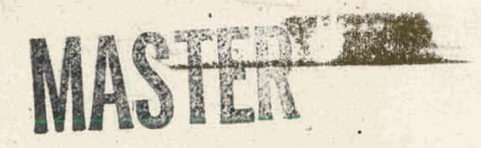

$$
\text { CONF-801114-. } 9
$$

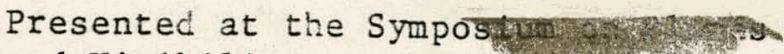
and Visibility: Measurements and Model Components, Grand Canyon, Arizona

Noul Oct. 10-14, 1930

Also subrittted to

Atmospheric Environment

\title{
THE RELATIVE IMPORTANCE OF ATMOSPHERIC SULFATES AND NITRATES IN VISIBILITY REDUCTION*
}

I.N. Tang, W. T. Wong and H. R. Munkelwitz

Department of Energy and Environment Brookhaven National Laboratory Upton, New York 11973

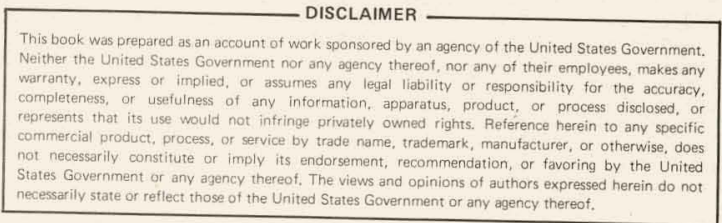

$*$

This research was performed under the auspices of the United States Department of Energy under Contract No. DE-AC02-76CH00016.

By acceptance of this article, the publisher and/or recipient acknowledges the U.S. Government's right to retain a nonexclusive, royalty-free license in and to any copyright covering this paper. 


\section{DISCLAIMER}

This report was prepared as an account of work sponsored by an agency of the United States Government. Neither the United States Government nor any agency Thereof, nor any of their employees, makes any warranty, express or implied, or assumes any legal liability or responsibility for the accuracy, completeness, or usefulness of any information, apparatus, product, or process disclosed, or represents that its use would not infringe privately owned rights. Reference herein to any specific commercial product, process, or service by trade name, trademark, manufacturer, or otherwise does not necessarily constitute or imply its endorsement, recommendation, or favoring by the United States Government or any agency thereof. The views and opinions of authors expressed herein do not necessarily state or reflect those of the United States Government or any agency thereof. 


\section{DISCLAIMER}

Portions of this document may be illegible in electronic image products. Images are produced from the best available original document. 
Abstract

Atmospheric visibility is largely determined by the concentration, size distribution, and chemical composition of the ambient aerosol. It has been shown by many investigators that sulfate compounds, which comprise a large mass fraction in the particle diameter range $0.1-1.0 \mu \mathrm{m}$, contribute most significantly to the light scattering properties of atmospheric aerosols: Several recent studies, in which visibility data are statistically analyzed to determine some other visibility reducing contributors, indicate that particulate nitrates may also be important. In an effort to ascertain the relative role that atmospheric sulfates and nitrates play in visibility reduction, total scattering coefficients are calculated for mixed-salt aerosols composed of various proportions of sulfates and nitrates under different humidity conditions. The thermodynamic and optical data required in the droplet growth and Mie calculations have been measured in laboratory experiments for the specific multicomponent systems of interest. The results of this study are compared with published empirical correlations to provide a physical basis for the observed variability of visibility data with chemical composition of the ambient aerosol. 
Introduction

The deterioration of atmospheric visibility, especially in urban centers and industrial areas, is but one of the consequences due to air pollution. The severity of the problem is expected to aggravate with the prospects of the accelerated use of fossil fuels in the next few years. In order to develop a control strategy for the conservation of our endangered environment, it is first necessary to delineate the important parameters governing the changes in air quality.

The extinction of light in the atmosphere by ambient aerosols is well known, and the major features of molecular and particle optics are reasonably well understood. Although in principle mathematical models can be constructed to calculate the optical properties of the atmosphere by considering the time and space variation of the chemical composition, concentration, and particlesize distribution of the ambient aerosol under prescribed meteorological conditions, such efforts at the present time are hampered by the fact that our knowledge of the chemistry and dynamics of ambient aerosols is still quite limited. Even for simple test cases dealing with the chemical equilibrium and phase transformation of a given multicomponent aerosol system, the thermodynamic and optical data required for model calculations are often lacking.

In the present paper, total scattering coefficients are calculated for mixed-salt aerosols composed of $\left(\mathrm{NH}_{4}\right)_{2} \mathrm{SO}_{4}$ and $\mathrm{Nh}_{4} \mathrm{NO}_{3}$ under various humidity conditions. Both external and internal mixtures of the aerosol components are considered. The thermodynamic and optical data needed for the droplet growth and Mie calculations were measured in separate experiments. The results are compared with published empirical correlations to provide a physical basis for the observed variability of visibility data with chemical composition of the ambient aerosol. 


\section{Characteristics of the Model Aerosols.}

Aerosol samples collected near urban locations contain a substantial portion of water-soluble salts of sulfate and nitrate, which have been shown by many investigators to correlate strongly with visibility reduction (Eggleton and Atkins, 1969; Waggoner et al., 1976; White, 1976; Patterson and Wagman, 1977; Barnes and Lee, 1978; Leaderer et al., 1979). These particulate sulfates and nitrates are formed either by the homogeneous oxidation of $\mathrm{SO}_{2}$ and $\mathrm{NO}_{2}$ in the gas phase, or by some heterogeneous processes in the aqueous phase of aerosol particles. Orel and Seinfeld (1977) and Peterson and Seinfeld (1979) have proposed a liquid-phase nitrate formation mechanism and a gas-phase sulfate formation mechanism for the urban atmosphere, and calculated the nitrate and sulfate levels in general agreement with the measurements by Appel et al., (1978) for the Los Angeles area. Tang (1980a) has recently studied the chemical equilibrium for the $\mathrm{NH}_{3}-\mathrm{HNO}_{3}-\mathrm{H}_{2} \mathrm{SO}_{4}-\mathrm{H}_{2} \mathrm{O}$ system and shown that the nitrate-tosulfate ratio in droplets depends strongly on droplet $\mathrm{pH}$ and the relative humidity of the atomsphere as well.

Thus, the chemical composition of ambient aerosols often varies with time, location, and atmospheric conditions. The ACHEX data reported by Appel et al., (1978) suggest that both sulfate and nitrate exist primarily as ammonium salts, with some evidence in support of unneutralized sulfates in the vicinity of sulfur oxide emissions. The nitrate levels in California's South Coast Air Basin are particularly high compared with other parts of the United States. The ACHEX data also show that sulfates consistently accumulate in the size fraction with mass median diameters of $0.3-0.4 \mu \mathrm{m}$, while nitrates tend to exhibit a broader size range, $0.3-1.6 \mu \mathrm{m}$. This distinct particle-size difference between sulfates and nitrates indicates that ambient aerosols in California are in most cases external mixtures rather than internal mixtures of component salts. 
The model aerosols chosen for the present study are composed of $76.8 \%$ by wt. $\left(\mathrm{NH}_{4}\right)_{2} \mathrm{SO}_{4}$ and $23.2 \%$ by wt. $\mathrm{NH}_{4} \mathrm{NO}_{3}$, which gives a molar sulfate-to-nitrate ratio of $2: 1$. Log-normal size distributions are assumed for all aerosols considered here. Thermodynamic and optical data for single salt solutions were taken from Robinson and Stokes (1970) and International Critical Tables (1933), while those for the mixed-salt solutions were measured at $25^{\circ} \mathrm{C}$ for the concentration range of $11.6-47.8 \%$ by wt total salt. The experimental procedures have previously been described (Tang and Munkelwitz, 1978).

The water acitivity $A_{w}$, density $\rho$, and refractive index $m$ of the mixed sulfate and nitrate solutions as a function of nitrate mass fraction $\mathrm{X}_{\mathrm{N}}$ are fitted using polynomials given as follows:

$$
\begin{array}{rlrl}
A_{w} & =5365.08 x_{N}^{3}+24.90 x_{N}^{2}-125.69 x_{N}+100 \\
& x_{N}<0.111 & \\
\rho= & 0.9970+2.1909 x_{N}, & x_{N}<0.111 \\
m=1.3337+0.450 x_{N}, & 0 \leq x_{N}<0.01 \\
=1.3321+0.606 x_{N}, & 0.01 \leq x_{N}<0.06 \\
=1.3341+0.573 x_{N}, & 0.06 \leq x_{N}<0.111
\end{array}
$$

Growth of Hygroscopic Aerosols by Water Vapor Condensation

It is well known that most inorganic salt aerosols exhibit the property of deliquescence upon exposure to a moist environment. The phase transition from a solid particle to a saline droplet occurs rather abruptly when the relative humidity reaches a specific value corresponding to the water activity of the saturated solution. The theory of droplet growth for single-component salt 
aerosols has been well established on the basis of thermodynamics (Kohler, 1936; orr, 1958). An example of single-salt aerosol growth is illustrated by ammonium sulfate as shown in Fig. 1, where the particle size change with reference to dry size $d_{0}$ is plotted as a function of relative humidity. The filled points represent the measured size change with increasing humidity, whereas the open points are droplet size changes measured when the relative humidity was gradually lowered. The experimental techniques employed in aerosol growth studies have been reported elsewhere (Tang et al., 1977). In this example, the properties of deliquescence at $79.5 \% \mathrm{R} . \mathrm{H}$. for $\left(\mathrm{NH}_{4}\right)_{2} \mathrm{SO}_{4}$ and the "hysteresis" phenomenon normally observed (Orr et al., 1958; Winkler and Junge, 1972) for inorganic salt aerosols during droplet evaporation are clearly demonstrated. In fact, "hysteresis". is responsible for the often noted lingering of smogs (LaMer and Cotson, 1953) below the humidities at which they first appeared. The lingering time could last for hours depending upon the extent of humidity lowering, and when crystallization did occur, it would occur spontaneously at a specific humidity (Tang, 1980b).

The growth of a mixed-salt aerosol is complicated by the fact that a solid salt particle may go through several regions of multiphase equilibria before it is completely dissolved to form a homogeneous solution droplet. A theoretical study of the thermodynamics of droplet growth for multicomponent inorganic salt aerosols has recently been undertaken (Tang, 1976), and growth characteristics have been measured for some atmospheric aerosols (Winkler, 1973) and for aerosols generated from artificial salt mixtures such as chlorides and sulfates (Winkler and Junge, 1972; Tang et al., 1978).

The growth characteristics for the model aerosol considered in the present study can be best understood by referring to the solubility diagram shown in Fig. 2 for the $\mathrm{NH}_{4} \mathrm{NO}_{3}-\left(\mathrm{NH}_{4}\right)_{2} \mathrm{SO}_{4}-\mathrm{H}_{2} \mathrm{O}$ system. The diagram was constructed from 
data tabulated by Seidell and Linke (1965). The diagonal line represents the composition of dry salt mixtures, and the other heavy line is the solubility curve marked with three eutonic points $E_{1}, E_{2}$ and $E_{3}$. To the left of the solubility curve is the homogeneous solution region, and to its right are multiphase regions that a dry salt particle must pass through upon exposure to an increasingly humid environment. The model aerosol used in the present study as an internal mixture has its composition represented by point $A$ on the diagonal 1ine. It will grow in size by water vapor condensation along the line $A B C O$. The first deliquescence point occurs at $B$ when the relative humidity reaches a value determined by the water activity of the eutonic point $E_{3}$. This deliquescence humidity has been determined to be $56: 4 \%$ in an earlier study (Tang, 1980b). The second-stage growth occurs at point $C$ when the humidity reaches $77.5 \%$, by which time the salt particle has become a saturated solution droplet. Subsequent growth will be smooth as the relative humidity increases. Since in the present study the thermodynamic and optical properties have been measured only within the homogeneous solution region along line $\mathrm{CO}$, the extinction coefficient calculations for the case of internal mixtures are also limited to this region.

Extinction Coefficient Calculations

The total extinction coefficient, bext, for an aerosol of given size distribution, $f(D)$, with respect to diameter $D$ was computed using the following equation,

$$
b_{\text {ext }}=\int_{0}^{\infty} \pi\left(\frac{D}{2}\right)^{2} Q_{\text {ext }}(\alpha, m) N f(D) d D
$$

where

$$
\begin{aligned}
& \alpha=\frac{\pi D}{\lambda} \\
& N=\text { particle number density } \\
& \text { Qext }(\alpha, m)=\text { extinction coefficient for given } \alpha \text { and refractive index } m .
\end{aligned}
$$


Throughout the study, a constant dry salt loading of $1 \mu \mathrm{g} / \mathrm{M}^{3}$ was employed as the basis of computation. The wavelength; $\lambda=0.580 \mu \mathrm{m}$, was chosen as recommended by Presle and Horvath (1978). Qext values were computed exactly according to the Mile scattering theory.

The size change of a droplet as a function of relative humidity was computed from the equation,

$$
H=A_{W} \exp \left(\frac{\sigma M}{\rho R T D}\right)
$$

where $\mathrm{H}=$ relative humidity at temperature $\mathrm{T}$

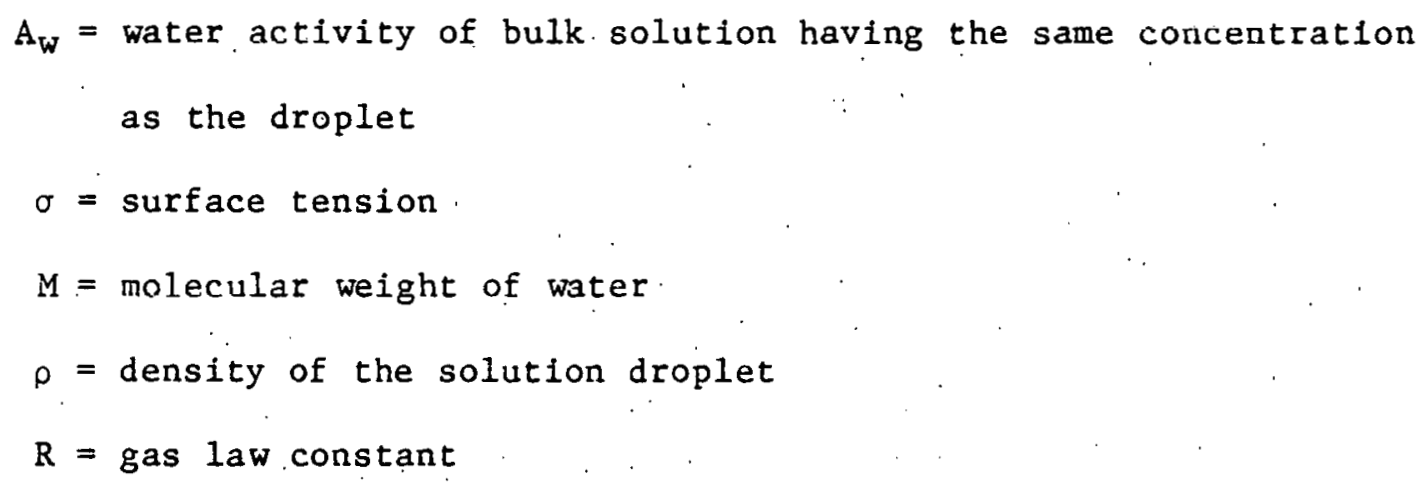

For the case of mixed-salt aerosols (internal-mixtures), the surface tension effect was not included in the calculation because of a lack of data. In general, the surface tension contribution to droplet growth is small for droplets larger than $0.1 \mu \mathrm{m}$ in diameter and may be ignored in light scattering calculations without introducing excessive errors.

The total extinction coefficient as a function of relative humidity was calculated for the following four cases:

Case 1. Ammonium. Sulfate aerosols with log normal distributions

$$
0.2 \leq D_{g} \leq 0.8, \quad 1.01 \leq \sigma_{\mathrm{g}} \leq 2.5
$$

Case 2. Ammonium nitrate aerosols with log-normal distributions

$$
0.2 \leq D_{\mathrm{g}} \leq 0.7, \quad 1.01 \leq \sigma_{\mathrm{g}} \leq 2.0
$$


Case 3. External mixtures of $\left(\mathrm{NH}_{4}\right)_{2} \mathrm{SO}_{4}$ and $\mathrm{NH}_{4} \mathrm{NO}_{3}$

Sulfate: $76.8 \%$ by wt.

$$
\mathrm{D}_{\mathrm{g}}=0.2, \sigma_{\mathrm{g}}=1.5
$$

Nitrate: $23.2 \%$ by wt.

$$
\mathrm{D}_{\mathrm{g}}=0.6, \sigma_{\mathrm{g}}=1.5
$$

The choice of the size distribution for each component salt is such that sulfate has a mass median diameter of $0.33 \mu \mathrm{m}$ and nitrate $0.98 \mu \mathrm{m}$, corresponding approximately to the bimodel distributions of the Los Angeles aerosols.

Case 4. Internal mixtures of $\left(\mathrm{NH}_{4}\right)_{2} \mathrm{SO}_{4}$ and $\mathrm{NH}_{4} \mathrm{NO}_{3}$ having the same dry salt composition as Case 3. Four different sịze distributions were considered:

$$
\begin{aligned}
& \text { (i) } \mathrm{D}_{\mathrm{g}}=0.2, \sigma_{\mathrm{g}}=1.5 \text {, same as the sulfate aerosol in Case } 3 \\
& \text { (ii) } \mathrm{D}_{\mathrm{g}}=0.6, \sigma_{\mathrm{g}}=1.5 \text {, same as the nitrate aerosol in Case } 3 \\
& \text { (iii) } \mathrm{D}_{\mathrm{g}}=0.29, \sigma_{\mathrm{g}}=1.5 \text {, which gives a mass median diameter of } \\
& 0.475 \mu \mathrm{m} \text {, the mass fraction average of the mass median } \\
& \text { diameters of (i) and (ii) } \\
& \text { (iv) } \mathrm{D}_{\mathrm{g}}=0.4, \sigma_{\mathrm{g}}=1.5 \text {, which gives a mass median diameter of } \\
& 0.65 \mu \mathrm{m}, \text { mid-way between that of (i) and (ii). }
\end{aligned}
$$

\section{Results and Discussions}

The results of extinction coefficient calculations for ammonium sulfate aerosols, as specified in Case 1, are shown in Fig. 3, in which bext is plotted vs . relative humidity for four different size distributions ranging from: monodisperse aerosols $\left(\sigma_{g}=1.01\right)$ to highly polydisperse aerosols $\left(\sigma_{g}=2.5\right)$. The deliquescence point at $80 \% \mathrm{R} . \mathrm{H}$. for $\left(\mathrm{NH}_{4}\right)_{2} \mathrm{SO}_{4}$ aerosols is clearly reflected in the extinction coefficient as well. In reality, however, the discontinuity 
at the deliquescence point may not be as pronounced since the droplets may remain in the supersaturated state as pointed out earlier: Garland (1969) has made similar calculations for $\left(\mathrm{NH}_{4}\right)_{2} \mathrm{SO}_{4}$ aerosols and obtained a smooth transition at the deliquescence point by using physical properties for supersaturated solutions extrapolated from data for the subsaturated region. No attempt was made in the present study to obtain extrapolated data for supersaturated solutions. Experimental techniques, however, are being developed to enable direct measurement of thermodynamic and optical properties for supersaturated solution droplets suspended in a laser beam (Tang and Munkelwitz, 1980).

The results obtained for ammonium nitrate aerosols, as specified in Case 2, are shown in Fig. 4. The deliquescence point at $62 \% \mathrm{R} . \mathrm{H}$. for $\mathrm{NH}_{4} \mathrm{NO}_{3}$ is al so noted. Fig. 5 shows the results calculated for Case 3 and Case 4, which are, respectively, externally and internally mixed sulfate and nitrate aerosols having identical mass loading. It is interesting to observe that for external mixtures, whose composition has been chosen to represent the average ambient mixture of sulfate and nitrate aerosols, the sulfate indeed contributes overwhelmingly to visibility reduction, a finding in support of general observations for atmospheric aerosols. The internal mixtures behave rather surprisingly as their extinction coefficient curves do not differ markedly, although there are substantial differences in particle size $\left(0.2 \leq \mathrm{D}_{\mathrm{g}} \leq 0.6\right)$. In addition, the extent of visibility reduction by aerosols as internal mixtures seems to be considerably less than that by similar aerosols present as external mixtures. More work is in progress to learn whether such contrast in light-scattering properties between Internally and externally mixed sulfate and nitrate aerosols persists for other compositions as well.

The characteristics of the extinction coefficient curves for these salt aerosols clearly suggest that the size change of the scatterers due to growth by 
water vapor condensation is mainly responsible for the increased light extinction with increasing relative humidity. Hidy et al., (1974) have shown empirically that light scattering by Los Angeles basin submicron aerosols is well correlated with total submicron'aerosol volume. For droplets several microns in diameter, however, light scattering depends more on the cross-sectional area than on the volume of the scatterer. Thus, Cass (1979) has used the following relationship to correlate the relative humidity with light scattering by various aerosol species including sulfates, nitrates, and other components which are insoluble in water:

$$
b_{\text {scat }}=\sum_{j} \frac{c_{j}}{\left(1-\frac{H}{100}\right)^{k_{j}}}
$$

where $C_{j}$ is a constant for each species, $j$, and the exponent $k_{j}$ may vary between 1 and $2 / 3$ for hygroscopic components. The same relationship was used by Neiburger and Wurtele (1949) in their study of sea-salt nuclei with $k$ fixed for 2/3. Using a non-linear regression model, Cass (1979) has determined the best $k$ value of 0.53 for sulfates and 1.09 for nitrates with the long-term data collected in Los Angeles. Cass's correlation is shown in Fig. 5 and compares rather favorably with the extinction curve calculated for the external mixtureschosen for the present study. Also shown in Fig. 5 is the correlation obtained by White and Roberts (1977) for some selected smog episodes in the Los Angeles air basin. Their correlation shows a rather weak dependence of light scattering on relative humidity.

It should be noted that the dependence of visibility on relative humidity is sti11 an unsettled question. Many investigators (Kasten, 1969; Hanel, 1972; Meszaros, 1977) have found definite relationships between vistbility reduction 
and relative humidity, while others (Horvath, 1978; Presle and P1rich, 1980) have presented data showing no correlation at all. Fitzgerald (1980) has recently made measurements of relative humidity, dry aerosol characteristics and the light scattering coefficient in the marine boundary layer of the North Atlantic, and showed that fluctuations in the concentration of dry aerosol particles made a greater contribution to the variability of the scattering coefficient than did fluctuations in relative humidity. On some occasions when the dry aerosol.characteristics were quite constant during a few hours, however, he was able to observe the kind of extinction coefficient curves in reasonable agreement with the growth curves of large and giant marlne aerosol particles. obtained by Winkler (1977).

The question, therefore, is not whether hygroscopic aerosols in the atmosphere will exhibit the growth characteristics expected of them. It is rather how to isolate the individual contributions by all the important variables. including relative humidity. Variables such as chemical composition and physical state of aerosols, their particle size distribution and number concentration as a furction of time, homogeneous and heterogeneous chemical reactions leading to aerosol formation, and whether the aerosol components are internally or externally mixed, will all play a role in atmospheric visibility. 


\section{References}

Appel, B.R., Kothny, E.L., Hoffer, E.M., Hidy, E.M., and Wesolowski, J.J. (1978) Sulfate and nitrate data from the California Aerosol Characterization Experiment (ACHEX). Envir. Sci. Technol. 12, 418-425.

Barnes, R.A. and Lee, D.O. (1978) Visibility in London and the long distance transport of atmospheric sulfur. Atm. Environ. 12, 791-794.

Cass, G.R. (1979) On the relationship between sulfate in air quality and visibility with examples in.Los Angeles. Atm. Environ. 13, 1069-1084.

Eggleton, A.E.J. and Atkins, D.H.F. (1969) The chemical composition of atmospheric aerosols on Tees-side and its relation to visibility. Atm. Environ. 3 , 355-372.

Fitzgerald, J.W. (1980) The relative contribution of fluctuations in relative humidity and particulate concentration to the variability of the scattering coefficient over the North Atlantic. Atm. Environ. 14, 71-77.

Garland, J.A. (1969) Condensation on ammonium sulfate particles and its effect on visibility. Atm. Environ. $3,347-354$.

Hanel, G. (1972) The ratio of the extinction coefficient to the mass of atmospheric aerosol particles as a function of the relative humidity. J. Aerosol Sci. 3 , 455-460.

Hidy, G.M. et al. (1974) Characterization of aerosols in California (ACHEX), Science Center, Rockwell International, prepared under California Air Resources Board Contract No. 358.

Horvath, H. (1978) A note on an attempt to explain the relation between visual range and relative humidity on the basis of aerosol measurements. J. Aerosol Sci. 9, 187-188.

Internation Critical Tables (1930), McGraw-Hill, New York.

Kasten, F. (1968) The influence of the aerosol size distribution and its change change with relative humidity on visibility. Beitr. Phys. Atmos. 41 , $33-51$.

Kohler, H. (1936) The nucleus in and the growth of hygroscopic droplets. Trans. Faraday Soc. 32, 1152-1161.

La Mer, V.K. and Costen, S. (1953) The growth and shrinkage of aerosols. Science $118,516-517$.

Leaderer, B.P., Holford,. T.R. and Stolwijk, J.A.J. (1979) Relationship between sulfate aerosol and visibility. J. Air Pollution Cont. Assoc. 29, 154-157. 
Meszaros, A. (1977) An attempt to explain the relation between visual range and relative humidity on the basis of aerosol measurements. J. Aerosol Sci. $\underline{8}$, $31-38$.

Neiburger, M. and Wurtele, M.G. (1949) On the nature and size of particles in haze, fog, and stratus of the Los Angeles Region. Chem. Rev. 44, 321-335.

Orr, C.Jr., Hurd, F.K. and Corbett, W.J. (1958) Aerosol Size and relative humidity. J. Colloid Sci.13, 472-482.

Orel, A.E. and Seinfeld, J.H. (1977) Nitrate formation in atmospheric aerosols. Envir. Sci. Technol. 11, 1000-1007.

Patterson, R.F. and Wagman, J. (1977) Mass and composition of an urban aerosol as a function of particle size for several visibility levels. J. Aerosol. Sci : $8,269-280$.

Peterson, T.N. and Seinfeld, J.H. (1979) Calculation of sulfate and nitrate levels in a growing, reacting aerosol. AIChE J. 25, 831-838.

Presle, G. and Horvath, H. (1978) Visibility in turbid media with colored illumination. Atm. Environ. 12, 2455-2459.

Presle, G. and Pirich, R. (1980) The relation between change of the extinction coefficient and relative humidity. J. Aerosol Sci. 11, 255-257.

Robinson, R.A. and Stokes, R.H. (1970) Electrolyte Solutions 2nd ed. Buttleworths, London.

Seidell, A. and Linke, W.F. (1965) Solubilities of inorganic and Metal Organic Compoinds. 4 th ed. Am. Chem. Soc.

Tang, I.N. (1976) Phase transformation and growth of aerosol particles composed of mixed salts. J. Aerosol Sci. $1,361-371$.

Tang, I.N. (1980a) On the equilibrium partial pressures of nitric acid and ammonia in the atmosphere. Atm. Environ. 14, 819-828.

Tang, I.N. (1980b) Deliquescence properties and particle size change of hygroscopic aerosols in Generation of Aerosols, edited by $K$. Willeke, Ann Arbor Sci. Publisher, Ann Arbor, Michigan. PP 153-167.

Tang; I.N. and Munkelwitz, H.R. (1978) The optical and thermodynamic properties of $\left(\mathrm{NH}_{4}\right)_{3}\left(\mathrm{SO}_{4}\right)_{2}$ (letovicite) aerosols, presented at the May 1978 Industrial Hyglene Conference, Los Angeles.

Tang, I.N. and Munkelwitz, H.R. (1980) Light-scattering experiments with siongle supersaturated $\mathrm{NaCl}$ solution droplets suspended in a laser beam, presented at the 13th Aerosol Technology Meeting, Boston. 
Tang, I.N., Munkelwitz, H.R. and Davis, J.G. (19.77) Aerosol growth studies II. preparation and growth measurements of monodisperse salt aerosols. J. Aerosol. Sci. 8, 149-159.

Tang, I.N., Munkelwitz, H.R. and Davis, J.G. (1978) Aerosol growth studies -IV. Phase transformation of mixed salt aerosols in a moist atmosphere. J. Aerosol Sci. 9, 505-511.

Waggoner, A.P., Vanderpol, A.J., Charlson, R.J., Larson, S., Granat, L. and Tragardgh C. (1976) Sulfate-light scattering as an index of the role of sulfur in tropospheric optics. Nature 261, 120-122.

White, W.H. (1976) Reduction of visibility by sulfates in photochemical smog. Nature $264,735-736$.

White, W.H. and Roberts, P.T. (1977) On the nature and origins of visibilityreducing aerosols in the Los Angeles atr basin. Atm. Environ. 11, 803-812.

Winkler, P. (1973) The growth of atmospheric aerosol particles as a function of the relative humidity - II. An improved concept of mixed nuclei. $\mathrm{J}$. Aerosol Sci. 4, 373-387.

Winkler, P. and Junge, C.d (1972) The growth of atmospheric aerosol particles as a function of the relative humidity - Part I: Method and measurements at different locations. J. Rect. Atm. 4, 617-638. 
PARTICLE SIZE CHANGE FOR $\left(\mathrm{NH}_{4}\right)_{2} \mathrm{SO}_{4}$

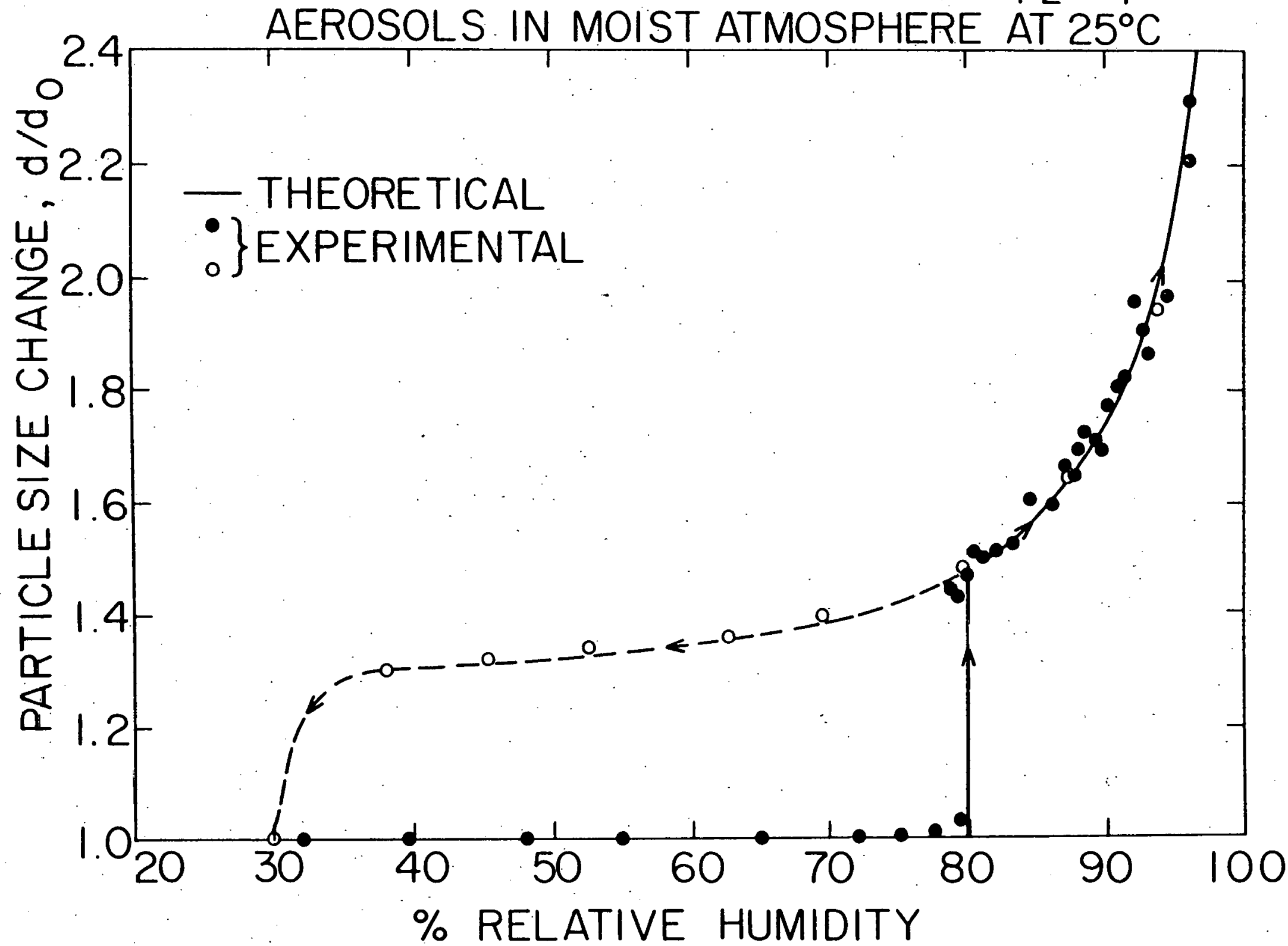




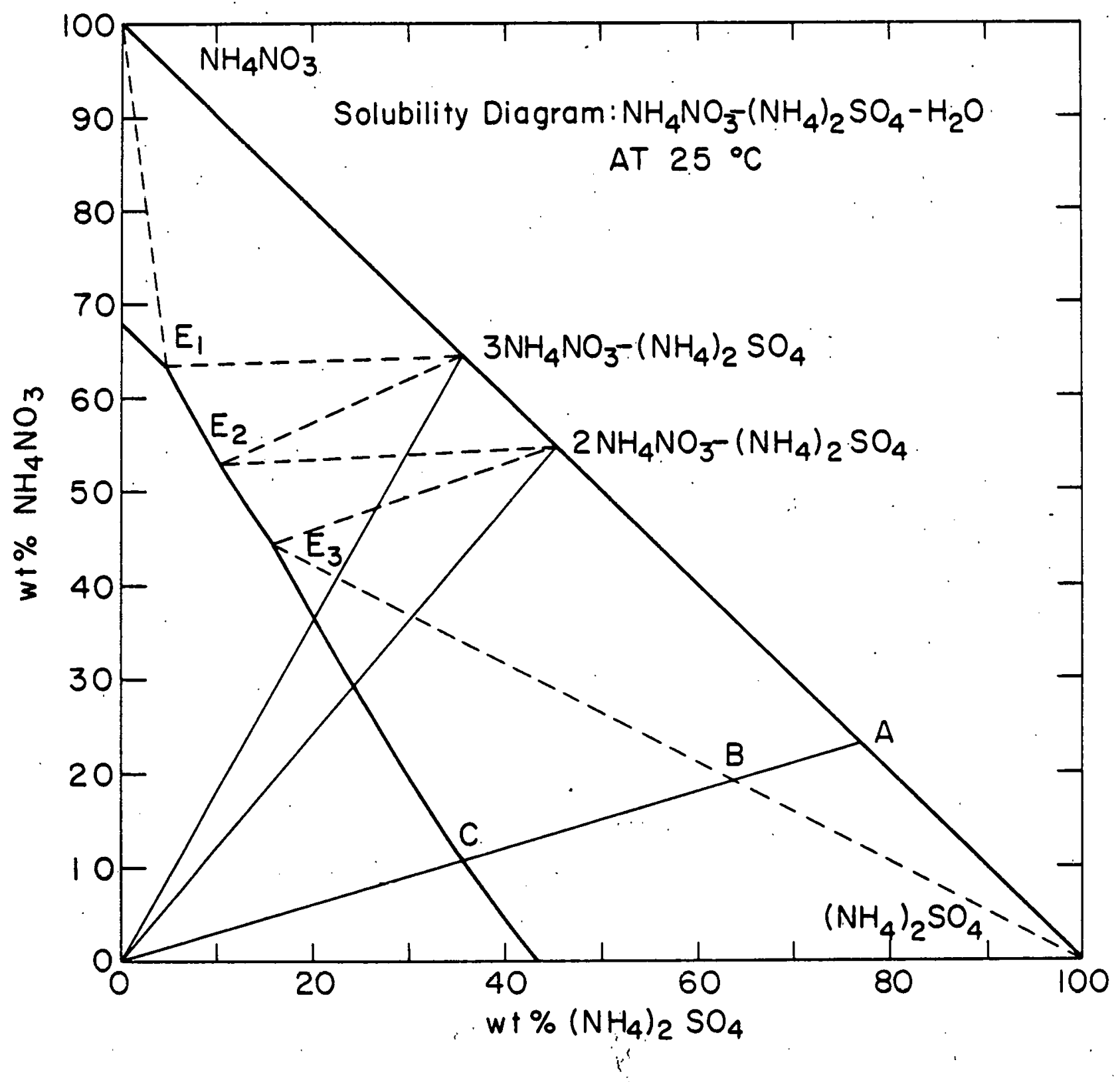

Fig. 2 . 


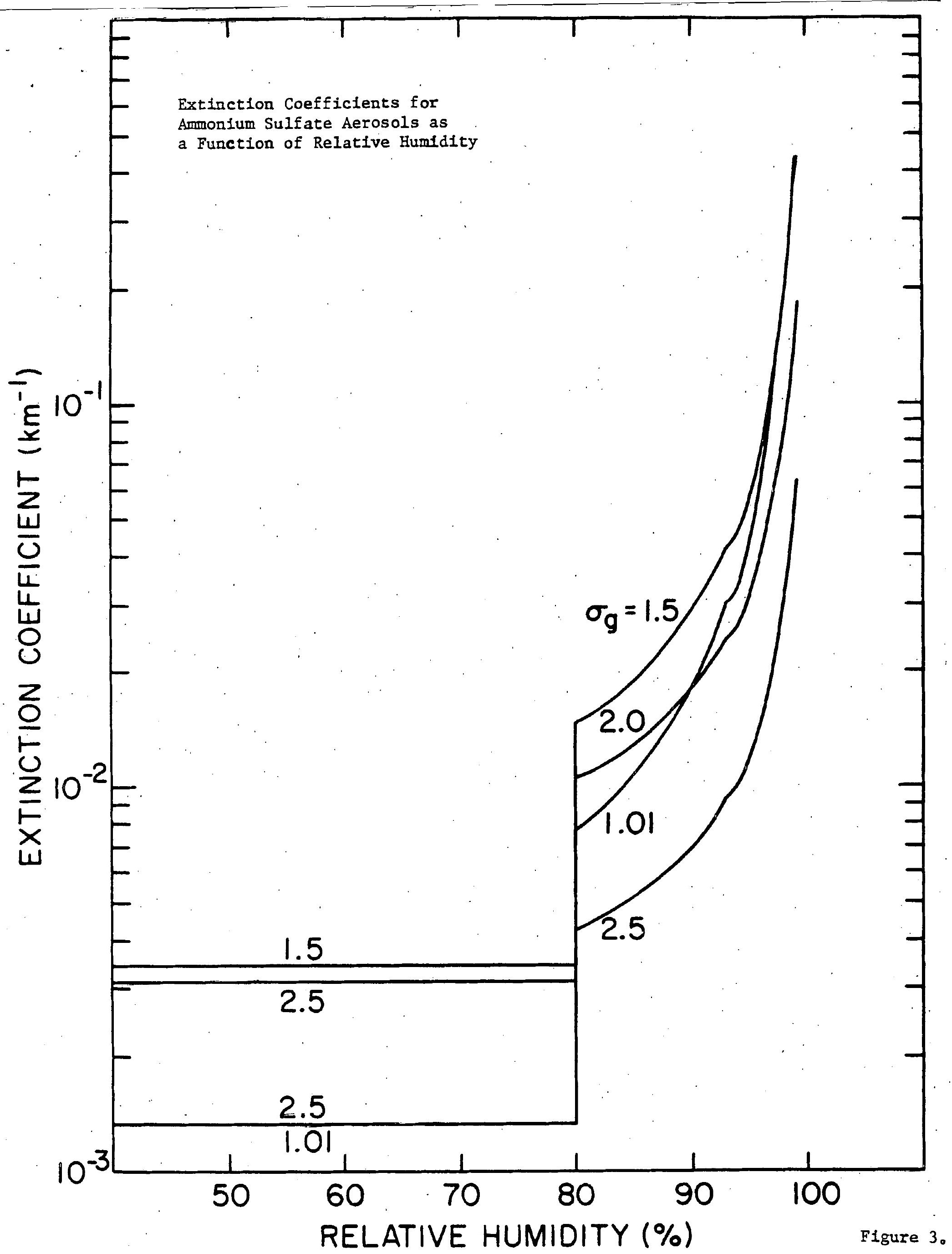




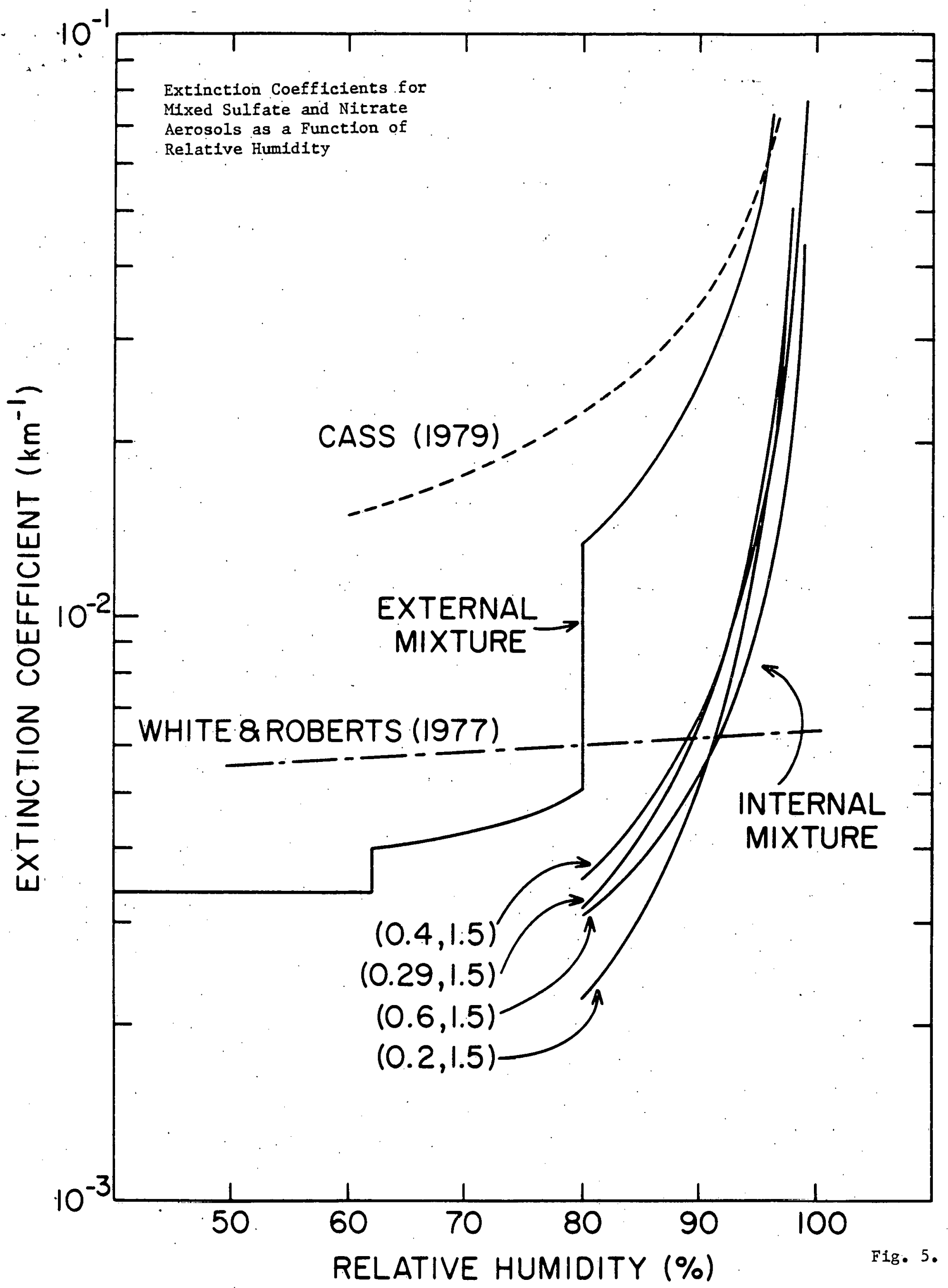

